\title{
Optimal Utilization of Light Energy in Semiclosed Greenhouse Using Three-Dimensional Cucumber Model
}

\author{
Tingting Qian,, ${ }^{1,2}$ Xiuguo Zheng, ${ }^{1,2}$ Juan Yang, ${ }^{1,2}$ Yeying Xu, ${ }^{1,2}$ Yan Wang, ${ }^{1,2}$ Qiang Zhou, ${ }^{1}$ \\ Shenglian Lu $\mathbb{D}^{3}{ }^{3}$ and Xiaotao Ding $\mathbb{D D}^{1}$ \\ ${ }^{1}$ Agricultural Information Institutes of Science and Technology, Shanghai Academy of Agriculture Sciences, \\ Shanghai 201403, China \\ ${ }^{2}$ Shanghai Engineering Research Center of Information Technology in Agriculture, Shanghai 201403, China \\ ${ }^{3}$ College of Computer Science and Information Technology, Guangxi Normal University, Guilin 541004, China
}

Correspondence should be addressed to Shenglian Lu; shll@126.com and Xiaotao Ding; xiaotao198108@163.com

Received 24 April 2020; Revised 16 June 2020; Accepted 9 July 2020; Published 1 August 2020

Academic Editor: Chenxi Huang

Copyright (C) 2020 Tingting Qian et al. This is an open access article distributed under the Creative Commons Attribution License, which permits unrestricted use, distribution, and reproduction in any medium, provided the original work is properly cited.

In the east of China, low temperature and light energy in winter are the main factors for the decline in cucumber yield, as well as in greenhouses without supplementary light. Optimal utilization of light energy is critical to increase cucumber yield. In this study, experimental measurements were conducted in two scenarios, April to May (Apr-May) and November to December (Nov-Dec) 2015, respectively, to analyze leaf development, dry matter accumulation, and yield of cultivated cucumber. Statistical analysis showed that leaves grew in Nov-Dec had larger leaf area and lower dry matter than leaves grew in Apr-May. This revealed that the dry matter accumulation rate per unit area was lower in winter. To be precise, the yield $0.174 \mathrm{~kg} / \mathrm{m}^{2}$ per day in Nov-Dec was $35.3 \%$ lower than the yield in Apr-May. Environmental monitoring data showed that there was no significant difference in the average temperature between two scenarios, but the light intensity in Nov-Dec was only 2/3 of that in Apr-May. Three-dimensional (3D) cucumber canopy models were used in this study to quantify the effects of weak light on dry matter production in Nov-Dec. Three $3 \mathrm{D}$ canopies of cucumber were reconstructed with 20,25, and 30 leaves per plant, respectively, by using a parametric modeling method. Light interception of three canopies from 8:00 to 15:00 on 4 November 2015 was simulated by using the radiosity-graphic combined model (RGM) with an hourly time step. $\mathrm{CO}_{2}$ assimilation per unit area was calculated using the FvCB photosynthetic model. As a result, the effects of light intensity and $\mathrm{CO}_{2}$ concentration on the photosynthetic rate were considered. The leaf photosynthesis simulation result showed that during the daytime in winter, the RuBP regeneration-limited assimilation $A_{j}$ was always less than the Rubisco-limited assimilation $A_{c}$. This means that the limiting factor affecting the photosynthesis rate in winter was rather light intensity. As the $\mathrm{CO}_{2}$ concentration in the greenhouse was utmost in the morning, increasing the light intensity and therefrom increasing the canopy light interception at this time will be highly beneficial to increase the yield production. Through a comparative analysis of photosynthetic characteristics in these three virtual 3D canopies, the 25-leaf canopy was the best-performed canopy structure in photosynthetic production in winter. This study provides an insight into the light deficiency for yield production in winter and a solution to make optimal use of light in the greenhouse.

\section{Introduction}

Cucumber is one of the most popular crops grown in facility agriculture. It requires relatively high light intensity and temperature. Low temperature and deficient light energy in winter in the east and north of China are the main factors for the decline of cucumber yield. With the promotion and application of semiclosed greenhouses in China, the excess solar energy in summer was collected and stored, and this energy should be reused to heat the greenhouse in winter [1]. As a result, the impact of low temperature in winter on yield has been greatly improved [2]. Nevertheless, in greenhouses without supplementary light, low light intensity remains an important cause affecting winter production [1]. For most greenhouse vegetables, $1 \%$ light increment results in $0.7-1 \%$ increase in harvestable product [3]. Therefore, optimal 
utilization of light energy should be critical for increasing the yield of cucumber in winter.

Optimization and control of the light environment in greenhouse have been widely studied. In order to increase the incident light intensity, supplementary light sources are often added on top of the canopy during the growing period as early as the 1980s [4]. For most greenhouse fruiting vegetables, such as cucumber and tomato, vegetative growth is concentrated on the top and middle of the canopy while reproductive growth occurs at the middle and bottom. In recent years, lighting strategies including light source type and distribution, spectral composition, and lighting duration have been widely studied. Hovi et al. [5] have shown that interlighting by using HPS (high-pressure sodium) can increase by $10 \%$ of cucumber fruit yield. However, these kinds of light sources are very difficult to be used as interlighting in narrow row arrangements, as they produce high heat. Hao et al. [6] studied the effect of HPS and LED (light-emitting diodes) light source and light position (on the top or inside of the canopy) on mini-cucumber growth rate and fruit yield. The result shows that the plants grown with LED interlighting achieved higher energy use efficiency than that with the top HPS. And, once canopy closure achieves, increasing total canopy light interception, especially increasing middle and lower light interception, is more conducive to yield [7].

In cucumber canopy, light interception is directly affected by canopy structure, which depends on plant growth and cultivation management. Accurate measurement of total light interception in the canopy has always been a great challenge. In previous studies, Beer-Lambert's law was widely used to calculate canopy light interception, but this law assumes that the canopy is a uniform medium, and ignored the influence of leaf distribution and inclination angle on light transmission [8]. For horticultural crops planted in rows, the canopy structure exhibits distinct heterogeneity. Since light distributes significantly different between and within crop rows, the orientation of the leaf directly determines its light interception [9]. The 3D structural model, which delivers a structure close to the real canopy, can accurately describe the distribution and location of organs in 3D space. Combing with ray casting, radiosity, and Monte Carlo ray-tracing approaches, local light conditions and light interception can be simulated at the leaf level and upscale to the canopy level [10]. Thus, the accuracy of the light interception estimation can be greatly improved.

Recent studies have shown that the 3D structural model is extremely useful for light interception-related calculation, for example, evaluating the effect of leaf area distribution and leaf angles on canopy light interception for "ideotype" selection $[11,12]$ and optimizing canopy structure pruning management [13]. In many FSPM (functional and structural plant models) research studies, 3D structural models were always combined with photosynthetic models and dry matter distribution models at the aim to design crops with higher yield potential and to enhance resource use efficiency [14-16].

In the present study, we combined 3D cucumber canopy model, ray-tracing method, and photosynthesis model together to analyze light conditions inside the canopy. By virtual experiments, we discussed a solution in greenhouse management to increase the photosynthetic production of cucumber crops in winter.

\section{Materials and Methods}

2.1. Field Experiments and Measurement on Plants. Field experiments were conducted in May and November 2015, respectively, in a semiclosed Venlo-type greenhouse at Shanghai Chongming Island (lat. $31^{\circ} 34^{\prime} \mathrm{N}$, long. $121^{\circ} 41^{\prime} \mathrm{E}$ ). The detailed information of the experimental greenhouse can be referenced in Ding et al. [2]. Mini-cucumbers (Cucumis Sativus L. cv. Deltastar) were planted on rockwool slabs along two parallel lines and each plant is located with a growing wire at a stem density of $2.8 \mathrm{stems} / \mathrm{m}^{2}$. Air temperature, relative humidity, and $\mathrm{CO}_{2}$ concentration in the greenhouse were recorded automatically at $5 \mathrm{~min}$ intervals using one climate sensor (Priva, De Lier, the Netherlands) per greenhouse, placed at the top of the canopy.

2.1.1. Measurement 1: Organ Developing Measurement. Two measurements were conducted in 2015 from $15^{\text {th }}$ April to $14^{\text {th }}$ May and from $4^{\text {th }}$ November to 3 December, and for convenience, Apr-May and Nov-Dec will be used to refer the two experimental scenarios, respectively, hereinafter. Every day in the experiment, five newly appeared phytomers, including an internode with the directly attached leaves and petioles, were selected to be marked as the initial point of organ expansion. In total, 150 phytomers corresponding to 450 organs were marked in the thirty consecutive days. Morphological measurements were performed on all marked phytomers, respectively, on May 16, 2015, and December 3, 2015. The measurement contents include leaf length (LL), leaf width (LW), petiole length (PL), petiole diameter (PD), internode length (IL), and internode diameter (ID). Leaf length was measured from the lamina tip to the intersection end of petiole along the lamina midrib. Leaf width was measured from tip to tip between the widest lamina lobes, as referenced in Cho et al. [17]. The diameter of the petiole and internode was measured in the middle of the organ. The manual measurement error is $\pm 1 \mathrm{~mm}$. After the measurement, the leaves and petioles were destructively dried and weighted.

2.1.2. Measurement 2: Canopy Structure Measurement. Canopy structure measurements were conducted on 4 November 2015. A total of 8 cucumber plants from 2 (rows) $* 4$ (plants) adjacent plants were selected, and all organs of the whole plant were measured manually. The measurement contents include leaf length, leaf width, petiole length, petiole diameter, internode length, and internode diameter. After the measurement, organs were segmented, dried, and weighed one by one.

\subsection{D Reconstruction of the Canopy}

2.2.1. Organ Expansion Modeling. Based on measurement 1, the least-squares method was used to fit statistical models for 
organ development. We used logistics function for leaf length, leaf width, petiole diameter, and internode diameter and Boltzmann function for petiole length, internode length, leaf dry weight (LDW), and petiole dry weight (PDW). The parameters of descriptive models for organ development are listed in Tables 1 and 2. The sum of the thermal time (GDD) is calculated independently: $\mathrm{GDD}=\sum\left(T-T_{\text {base }}\right) / 288$, where $T$ is the temperature measured by the sensor, $T_{\text {base }}$ is the base temperature, $10^{\circ} \mathrm{C}$ for mini-cucumber, and 288 is an invariant for the number of measurements per day. The duration is from the initial date till the end of measurement and valid temperature ranging from 10 to $40^{\circ} \mathrm{C}$ is applied for cucumber.

\subsubsection{Parametric Construction of 3D Cucumber Model.} Parameterized modeling method was used to construct the 3D cucumber canopies. The shape of each organ was determined by morphological parameters, which were generated by using the equations described above. Organ morphology was composed of skeletons and triangular mesh. B-splines curve was used to represent these skeletons in the computer. The control points on B-spline curve can determine the size of the organs (Figure 1), and the spatial distance of the control points was determined by the organ morphological parameters, which in turn determined the topology of the plant $[18,19]$.

2.2.3. 3D Canopy Construction for Cucumber. Three 3D canopies of cucumber were reconstructed with 20,25, and 30 leaves per plant, respectively, by using the parameterized modeling method. Each virtual canopy was consisted of sixteen plants (4 rows $* 4$ plants). The interplant distance in one line was $40 \mathrm{~cm}$, the line spacing was $70 \mathrm{~cm}$ (inside) and $110 \mathrm{~cm}$ (path), respectively (Figure 2).

2.3. Light Interception Modeling. Light interception of three canopies from 8:00 to 15:00 on 4 November 2015 was simulated by using the radiosity-graphic combined model (RGM) with an hourly time step. Distribution of 3D diffuse photosynthetically active radiation (DPAR) in the canopy was simulated discretely by dividing the sky hemisphere into a grid of fine cells that allowed for the anisotropic distribution of DPAR over the sky hemisphere. Diffuse radiation was calculated using the method of Wen et al. [10]. It was assumed that a leaf absorbs $87 \%$, transmits $7 \%$, and reflects $6 \%$ of the incident photosynthetically active radiation [15]. Total PAR and proportion of diffuse light intensity were measured using SunScan Canopy Analysis System (Delta Company, UK).

2.4. Leaf Photosynthesis Modeling. FvCB model (Farquhar-von Caemmerer-Berry biochemical photosynthesis model) was applied in leaf photosynthesis modeling. According to Farquhar et al. [20], assimilation rate $A$ is the minimum of the Rubisco-limited $\left(A_{c}, \mu \mathrm{mol} \cdot \mathrm{CO}_{2} \cdot \mathrm{m}^{-2} \cdot \mathrm{s}^{-1}\right)$ or RuBP regeneration-limited $\left(A_{j}, \mu \mathrm{mol} \cdot \mathrm{CO}_{2} \cdot \mathrm{m}^{-2} \cdot \mathrm{s}^{-1}\right)$ photosynthesis rate:

$$
\begin{aligned}
A_{c} & =\frac{V_{c \max } \cdot\left(C_{c}-\Gamma^{*}\right)}{\left[C_{c}+K_{c} \cdot\left(1+O / K_{0}\right)\right]-R_{d}}, \\
A_{j} & =\frac{J \cdot\left(C_{c}-\Gamma^{*}\right)}{\left(4 C_{c}+8 \Gamma^{*}\right)-R_{d}},
\end{aligned}
$$

where $C_{c}$ (chloroplastic $\mathrm{CO}_{2}$ concentration, $\mu \mathrm{mol} \cdot \mathrm{mol}^{-1}$ ) is calculated by using the following equation:

$$
C_{c}=\frac{C_{i}-A}{g_{m}} .
$$

When substituting equation (3) into equations (1) and (2), we get the quadratic equation of variable $A_{c}$ and $A_{j}$, and the solutions are as follows:

$$
\begin{aligned}
A_{c} & =\frac{-b-\sqrt{b^{2}-4 a c}}{2 a}, \\
a & =\frac{1}{g_{m}}, \\
b & =\frac{\left(R_{d}-V_{c \max }\right)}{g_{m}-C_{i}-K_{c}\left(1+O / K_{0}\right)}, \\
c & =V_{c \max }\left(C_{i}-\Gamma^{*}\right)-R_{d}\left[C_{i}+K_{c}\left(\frac{1+O}{K_{0}}\right)\right], \\
A_{j} & =\frac{-b-\sqrt{b^{2}-4 a c}}{2 a}, \\
a & =\frac{4}{g_{m}}, \\
b & =\frac{\left(4 R_{d}-J\right)}{g_{m}-4 C_{i}-8 \Gamma^{*}}, \\
c & =J\left(C_{i}-\Gamma^{*}\right)-4 R_{d}\left(C_{i}+2 \Gamma^{*}\right) .
\end{aligned}
$$

$J$ (rate of electron transport, $\mu \mathrm{mol} \cdot \mathrm{m}^{-2} \mathrm{~s}^{-1}$ ) was calculated by the following equation:

$$
J=\frac{\left(K \cdot I+J_{\max }-\sqrt{\left(K \cdot I+J_{\max }\right)^{2}-4 \theta \cdot J_{\max } \cdot K \cdot I}\right)}{2 \theta},
$$

where $V_{c \max }$ is the maximum rate of Rubisco carboxylation $\left(130.84 \mu \mathrm{mol} \cdot \mathrm{CO}_{2} \cdot \mathrm{m}^{-2} \cdot \mathrm{s}^{-1}\right) ; \Gamma^{*}$ is the $\mathrm{CO}_{2}$ compensation point in the absence of dark respiration $\left(43.02 \mu \mathrm{mol} \cdot \mathrm{mol}^{-1}\right)$; $K_{c} \quad\left(404 \mu \mathrm{mol} \cdot \mathrm{mol}^{-1}\right)$ and $K_{o} \quad\left(278 \mathrm{mmol} \cdot \mathrm{mol}^{-1}\right)$ are Michaelis-Menten constants of Rubisco for $\mathrm{CO}_{2}$ and $\mathrm{O}_{2} ; \mathrm{O}$ is the mole fraction of $\mathrm{O}_{2}$ at the site of carboxylation $\left(210 \mathrm{mmol} \cdot \mathrm{mol}^{-1}\right) ; \quad R_{d}$ is the respiration rate $(1.08$ $\left.\mu \mathrm{mol} \cdot \mathrm{CO}_{2} \cdot \mathrm{m}^{-2} \cdot \mathrm{s}^{-1}\right) ; \quad g_{m}$ is mesophyll conductance $\left(0.8 \mathrm{~mol} \cdot \mathrm{m}^{-2} \cdot \mathrm{s}^{-1}\right) ; C_{i}$ is ambient $\mathrm{CO}_{2}$ concentration measured by $\mathrm{CO}_{2}$ sensor; $J_{\max }$ is the maximum electron transport rate $\left(125.66 \mu \mathrm{mol} \cdot \mathrm{m}^{-2} \cdot \mathrm{s}^{-1}\right) ; \mathrm{K}$ is a constant describing the conversion efficiency of intercepted PAR $(I)$ to $J$ $\left(0.425 \mathrm{~mol} \cdot \mathrm{mol}^{-1}\right.$ photon $)$; and $\theta$ is a constant convexity factor describing the response of $J$ to $I(0.7)$ [15].

2.5. Model Calibration and Validation. The structural parameters measured in measurement 2 were used for model 
TABLE 1: Equations and parameter values of organ expansion in Apr-May.

\begin{tabular}{|c|c|c|c|c|c|c|c|}
\hline \multirow{2}{*}{ Equation } & \multirow{2}{*}{ Dependent variables $(y)$} & \multirow{2}{*}{ Independent variables $(x)$} & \multicolumn{4}{|c|}{ Parameter value } & \multirow{2}{*}{$R^{2}$} \\
\hline & & & $a$ & $b$ & & & \\
\hline \multirow{4}{*}{$y=a / 1+b e^{-k x}$} & LL & GDD & 26.30 & 4.21 & \multicolumn{2}{|c|}{0.025} & 0.983 \\
\hline & LW & GDD & 31.78 & 5.38 & \multicolumn{2}{|c|}{0.029} & 0.980 \\
\hline & $\mathrm{PD}$ & GDD & 7.91 & 2.61 & \multicolumn{2}{|c|}{0.003} & 0.915 \\
\hline & ID & GDD & 8.13 & 2.81 & \multicolumn{2}{|c|}{0.039} & 0.951 \\
\hline \multirow{5}{*}{$y=A_{1}-A_{2} / 1+e^{\left(x-x_{0}\right) / \mathrm{d} x}+A_{2}$} & & & $A_{1}$ & $A_{2}$ & $x_{0}$ & $\mathrm{~d} x$ & \\
\hline & PL & GDD & -8.01 & 32.17 & 67.08 & 47.69 & 0.989 \\
\hline & IL & GDD & -4.09 & 11.69 & 20.62 & 48.84 & 0.862 \\
\hline & LDW & GDD & -0.09 & 1.91 & 90.04 & 33.05 & 0.958 \\
\hline & PDW & GDD & -0.04 & 0.68 & 124.9 & 41.35 & 0.974 \\
\hline
\end{tabular}

TABle 2: Equations and parameters of organ expansion in Nov-Dec.

\begin{tabular}{|c|c|c|c|c|c|c|c|}
\hline \multirow{2}{*}{ Equation } & \multirow{2}{*}{ Dependent variables $(y)$} & \multirow{2}{*}{ Independent variables $(x)$} & \multicolumn{4}{|c|}{ Parameter value } & \multirow{2}{*}{$R^{2}$} \\
\hline & & & $a$ & $b$ & & & \\
\hline \multirow{4}{*}{$y=a / 1+b e^{-k x}$} & LL & GDD & 29.43 & 4.21 & \multicolumn{2}{|c|}{0.030} & 0.986 \\
\hline & LW & GDD & 33.49 & 5.40 & \multicolumn{2}{|c|}{0.035} & 0.977 \\
\hline & $\mathrm{PD}$ & GDD & 7.65 & 2.28 & \multicolumn{2}{|c|}{0.022} & 0.981 \\
\hline & ID & GDD & 7.69 & 1.98 & \multicolumn{2}{|c|}{0.094} & 0.898 \\
\hline \multirow{5}{*}{$y=A_{1}-A_{2} / 1+e^{\left(x-x_{0}\right) / \mathrm{d} x}+A_{2}$} & & & $A_{1}$ & $A_{2}$ & $X_{0}$ & $\mathrm{~d} x$ & \\
\hline & PL & GDD & -7.92 & 28.52 & 51.72 & 41.88 & 0.982 \\
\hline & IL & GDD & 1.04 & 11.33 & 26.97 & 12.20 & 0.802 \\
\hline & LDW & GDD & -0.003 & 1.38 & 67.73 & 22.98 & 0.964 \\
\hline & PDW & GDD & -0.01 & 0.44 & 92.92 & 26.00 & 0.984 \\
\hline
\end{tabular}

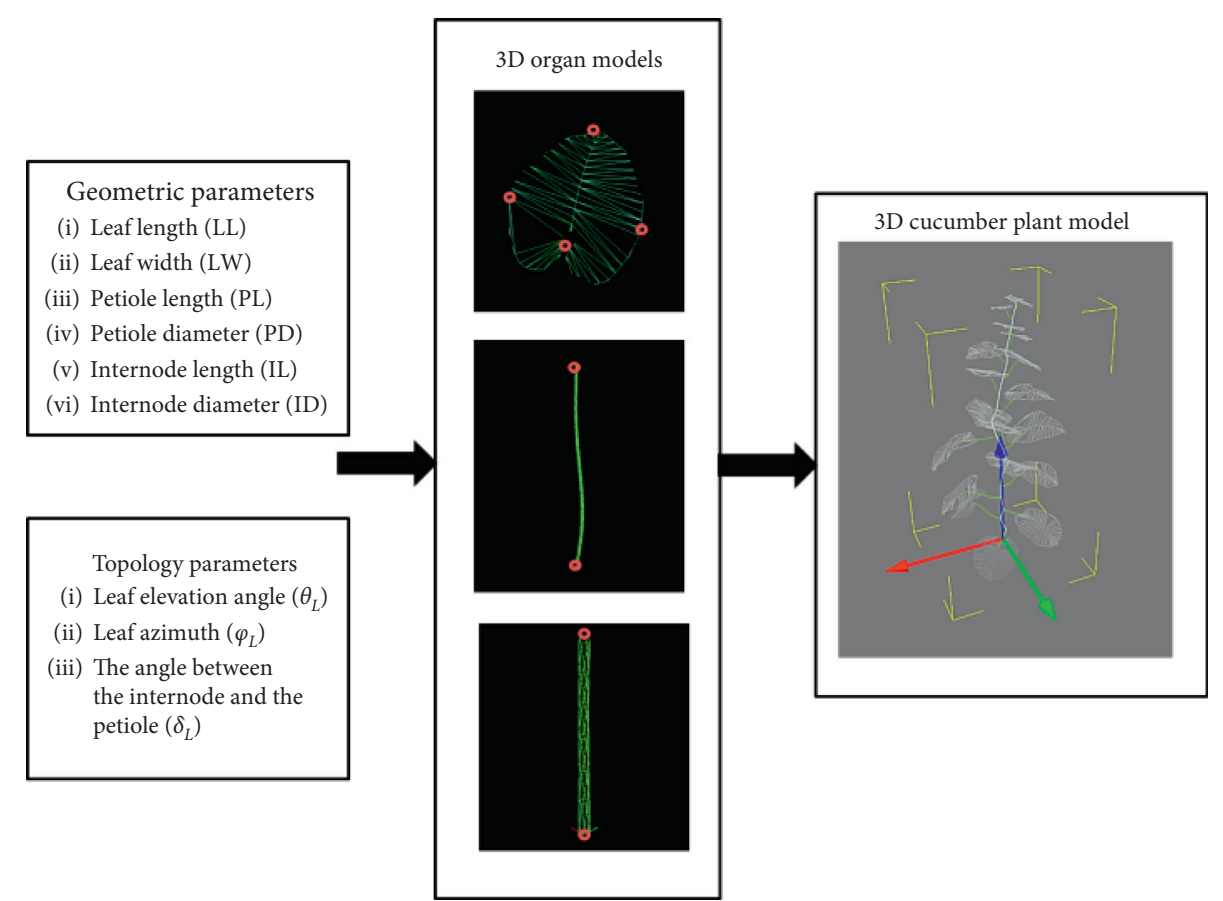

FIGURE 1: The workflow of reconstruction based on statistical models. The geometric parameters of blade, petiole, and internode came from equations of Tables 1 and 2, while the topology parameters of the angle between organs came from our former study of Qian et al. [18]. The spatial shape of the blade was determined by LL, LW, $\theta_{L}$, and $\varphi_{L}$; the spatial shape of the petiole was determined by PL and PD and $\delta_{L}$; the spatial shape of the internode was determined by IL and ID. 


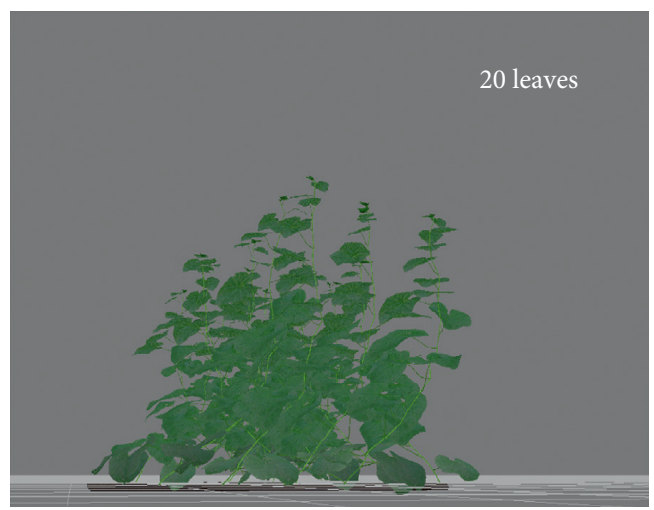

(a)

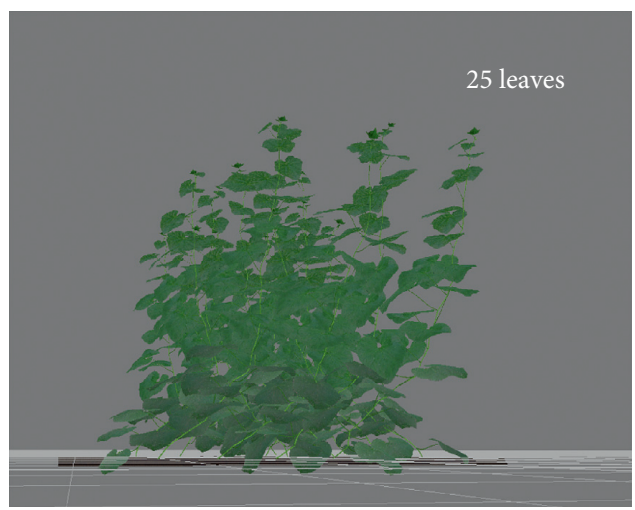

(b)

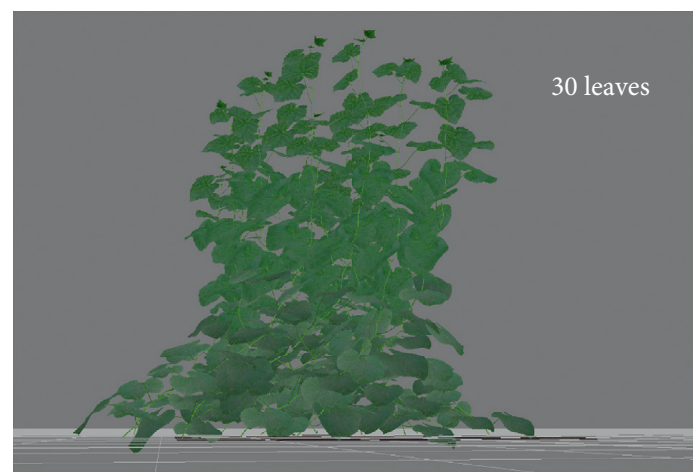

(c)

Figure 2: 3D canopies of sixteen cucumbers with 20, 25, and 30 leaves per plant, respectively.

validation. The root-mean-squared deviation (RMSD), bias, and accuracy (\%) were determined following the approach described by Kahlen and Stützel [21]:

$$
\begin{aligned}
\mathrm{RMSD} & =\sqrt{\frac{1}{n} \sum_{i=1}^{n}\left(x_{i}-y_{i}\right)^{2},} \\
\text { bias } & =\frac{1}{n} \sum_{i=1}^{n}\left(x_{i}\right)^{2}-\frac{1}{n} \sum_{i=1}^{n}\left(y_{i}\right)^{2}, \\
\text { accuracy } & =1-\frac{\mathrm{RMSD}}{(1 / n) \sum_{i=1}^{n} y_{i}},
\end{aligned}
$$

where $x_{i}$ and $y_{i}$ are the simulated and measured values, respectively. $n$ is the number of simulated or measured values.

\section{Results}

3.1. Organ Development Analysis. The growth of cucumber organs conforms to the sigmoid growth curve. The maximum asymptote $(y=\max )$, the maximum growth rate point $\left(x_{0}, y_{0}\right)$, and the slope $\left(y_{0}^{\prime}\right)$ at the inflection point can be used as characteristic values describing its growth process (Figure 3). The curve characteristic values based on the results of measurement 1 are shown in Table 3 and Figure 4. The $y_{0}^{\prime}$ of the leaf area expansion curves in Apr-May was
4.58, while the maximum expansion rate of leaf area occurs when the GDD reaches $92.75 \mathrm{Cd}$ (Figure 4(a)). The maximum expansion rate of the petiole and internode length in Apr-May was 0.21 and 0.30 , while the maximum expansion rate of the petiole appears at $67 \mathrm{Cd}$, and the maximum expansion rate of the internode appears at $41 \mathrm{Cd}$ (Figure 4(c)). It indicated that internode reaches the maximum expansion rate before leaf and petiole reaching the maximum expansion rate, and the elongation of the internode is nearly completed. The dry matter accumulation of the petiole was less than that of the leaf, and the maximum values were $0.68 \mathrm{~g}$ and $1.91 \mathrm{~g}$, respectively (Figure $4(\mathrm{~b})$ ). The dry matter of the leaf was 3 times the weight of the petiole.

The leaf expansion curve of cucumber in Nov-Dec was similar to that of Apr-May, and the leaf length expansion rate was lower than that of leaf width. Different from AprMay, the maximum leaf expansion rate in Nov-Dec occurred when GDD reached $76 \mathrm{Cd}$, earlier than Apr-May. The maximum expansion rates of petiole length and internode length were both 0.21 . The maximum expansion rate of the petiole appeared at $52 \mathrm{Cd}$, while the maximum expansion rate of the internode appeared at $27 \mathrm{Cd}$. In Nov-Dec, the maximum dry matter accumulation of petiole was $0.44 \mathrm{~g}$ and $1.38 \mathrm{~g}$, and the maximum dry matter accumulation in winter leaf was significantly smaller than that in Apr-May (Table 3).

3.2. Analysis of Differences in Organ Development in Different Scenarios. The rate of leaf area expansion in Apr-May was 


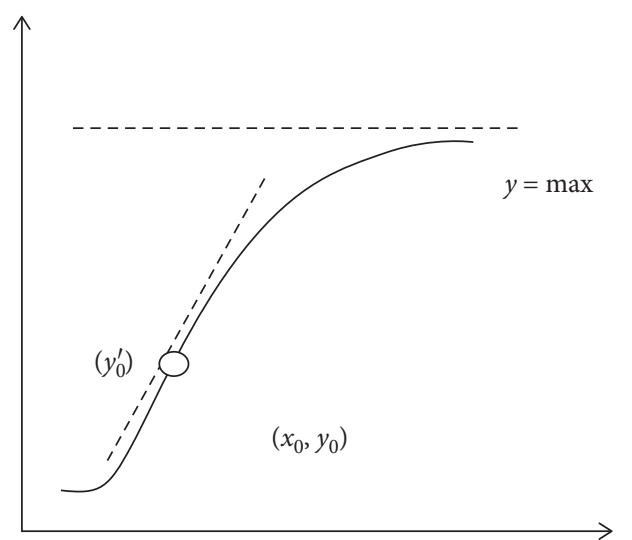

FIGURE 3: Sigmoid growth curve of organ expansion. $y=\max$ is the asymptote at the top of the curve, which represents the theoretical maximum value of organ expansion; $\left(x_{0}, y_{0}\right)$ is the inflection point of the curve, which represents the point when the organ expansion reaches the maximum rate; $y_{0}^{\prime}$ is the slope at the inflection point and represents the maximum rate of organ expansion.

TABle 3: Characteristic parameters of the organ expansion curve.

\begin{tabular}{ccccc}
\hline & Parameters & $y=\max$ & $y_{0}^{\prime}$ & $x_{0}, y_{0}$ \\
\hline \multirow{7}{*}{ Apr-May } & Leaf area & 625.95 & 4.58 & $92.75,312.97$ \\
& Leaf dry matter & 1.91 & 0.02 & $90.05,0.91$ \\
& Petiole length & 32.17 & 0.21 & 67.0812 .08 \\
& Internode length & 10.75 & 0.30 & 41.926 .07 \\
& Petiole diameter & 7.91 & 0.04 & $53.78,3.95$ \\
& Internode diameter & 8.13 & 0.08 & $26.70,4.06$ \\
\hline \multirow{5}{*}{ Nov-Dec } & Leaf area & 730.09 & 6.83 & $76.58,365.05$ \\
& Leaf dry weight & 1.38 & 0.01 & $67.73,0.69$ \\
& Petiole length & 28.52 & 0.21 & $51.72,10.30$ \\
& Internode length & 11.33 & 0.21 & $26.97,6.19$ \\
& Petiole diameter & 7.65 & 0.04 & $40.37,3.82$ \\
& Internode diameter & 7.69 & 0.18 & $7.13,3.84$ \\
\hline
\end{tabular}

less than that in Nov-Dec, while the dry weight of leaves was greater in Apr-May than in Nov-Dec (Figure 4). That is, the leaf dry matter per unit area in Apr-May was greater than that in Nov-Dec. From the changing trend of the dry matter accumulation curve, there was unobvious difference between the dry matter accumulation in the early Apr-May and Nov-Dec, but the rapid growth period of the dry matter accumulation curve in Apr-May was obviously longer than that in Nov-Dec. Therefore, the accumulation ratio of leaf dry weight per unit area was greater in Apr-May than in Nov-Dec (Figure 5). The elongation of the petiole and internode had no significant difference in the two scenarios. Although the diameter change of the petiole and internode was slightly different during the expansion period, the final diameter was still relatively close, with no obvious difference.

3.3. Methodological Accuracy of Organ Expansion Models. The data obtained in experiment 2 was used for model verification. The relationship between the measured and simulated values of leaf length, leaf width, petiole length, and internode length is shown in Figure 6, while the bias, RMSD, and accuracy of the model simplifications are shown in Table 4 . The simulated value was close to the measured value, and the accuracy of the four simulations was higher than 0.99 .

\subsection{Analysis of Leaf Light Interception and Photosynthetic} Characteristics in $3 D$ Canopies. Comparing the temperature and light environment conditions between Apr-May and Nov-Dec, the temperature difference was small, but the light difference was large. Since light directly participates in photosynthetic reactions during the accumulation of dry matter, there was a significant difference in yield in Apr-May and Nov-Dec (Figure 7). The yield was $0.174 \mathrm{~kg} / \mathrm{m}^{2}$ per day in Nov-Dec and it was 35.3\% lower than the yield in AprMay. To further analyze the canopy photosynthesis characteristics, it is necessary to combine the canopy radiation interception model and photosynthesis model.

In this study, light interception of three canopies from 8:00 to $15: 00$ on 4 November 2015 was simulated by using the radiosity-graphic combined model. Combining the 3D structure model and the radiosity-graphic combined model, the instantaneous light interception of each cucumber leaf in the canopy was calculated. The light interception data of the leaves of 4 plants inside the canopy were selected for analysis. The blocking effect of the surroundings was fully considered. The average light interception of a single leaf is shown in Figure 8. The light interception of the middle and lower canopy leaves was significantly lower than that of the upper part, and the light of the top leaves was relatively small due to the small leaf area. The lower leaves in the 20-leaf canopy have lower light interception than the other two canopies. The difference in light interception between the three upper canopy leaves was not obvious.

FvCB photosynthesis model was used in leaf assimilation rate modeling considering carbon dioxide assimilation mechanisms. The light interception of each blade calculated from the light interception simulation is input into the $\mathrm{FvCB}$ model as the incident light intensity $(I)$. The FvCB model calculates the assimilation rate of Rubisco-limited $\left(A_{c}\right.$, $\left.\mu \mathrm{mol} \cdot \mathrm{CO}_{2} \cdot \mathrm{m}^{-2} \cdot \mathrm{s}^{-1}\right)$ and RuBP regeneration-limited $\left(A_{j}\right.$, $\left.\mu \mathrm{mol} \cdot \mathrm{CO}_{2} \cdot \mathrm{m}^{-2} \cdot \mathrm{s}^{-1}\right)$, respectively. The data showed that during the daytime in Nov-Dec, the $A_{j}$ value was always less than the $A_{c}$ value. It means that the limiting factor affecting the photosynthesis rate in Nov-Dec was light intensity. The high concentration of $\mathrm{CO}_{2}$ in the morning can also promote photosynthesis (Figure 9). In the morning and afternoon, light intensity was only about half of the noon, while the photosynthesis rate was about $85 \%$ of noon. High $\mathrm{CO}_{2}$ concentration can make up part of the effect of low light intensity on the photosynthetic rate in Nov-Dec. There was no significant difference in the photosynthetic rate of the upper leaves of the three canopies, but affected by the light interception of the leaves, the photosynthetic rate of the lower leaves of the 20-leaf canopy was significantly lower than that of the other two canopies.

\section{Discussion}

4.1. The Contribution of 3D Model in Simulation Research. In the light interception calculation, the consistency of the 3D model and the true structure of the canopy is a crucial 


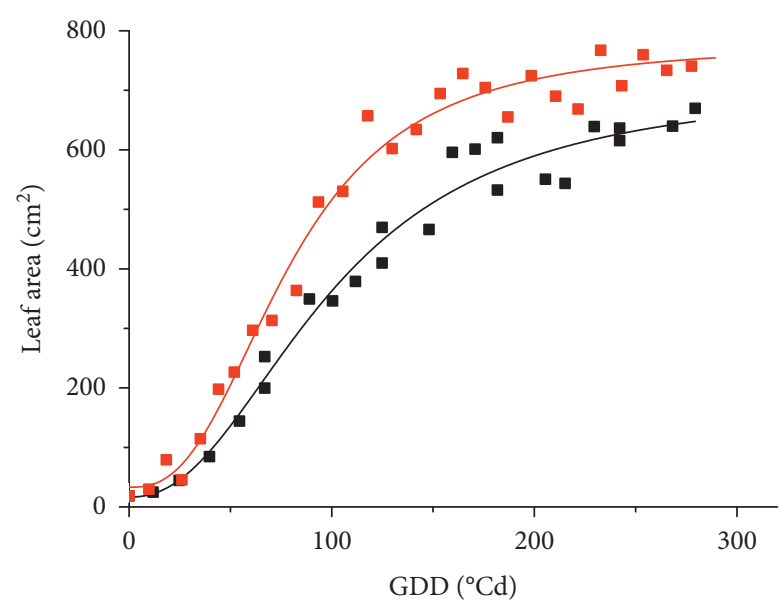

- Measured (Apr-May) - Measured (Nov-Dec) — Logistics fitted _ Logistics fitted

(a)

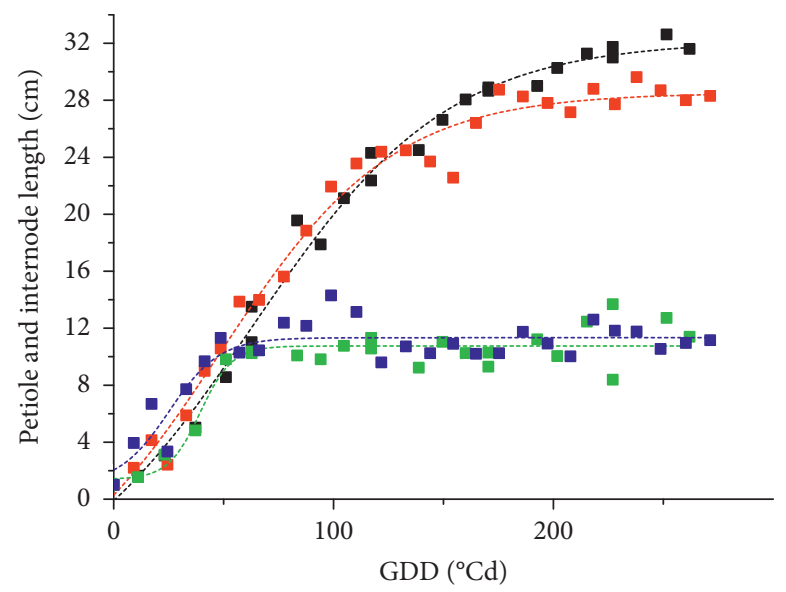

- Petiole length in Apr-May Boltzmann fitted

- Petiole length in Nov-Dec Boltzmann fitted

- Internode length in Apr-May

.... Boltzmann fitted

- Internode length in Nov-Dec ..... Boltzmann fitted

(c)

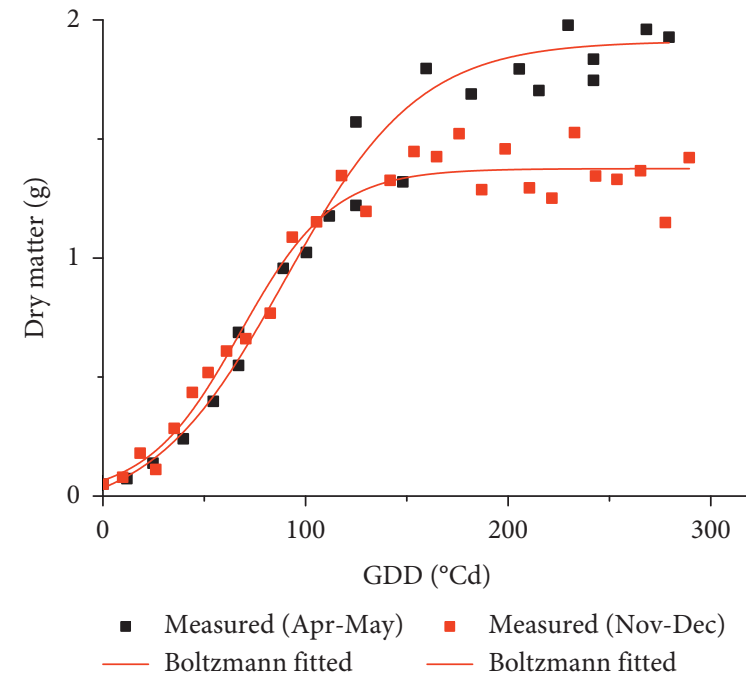

(b)

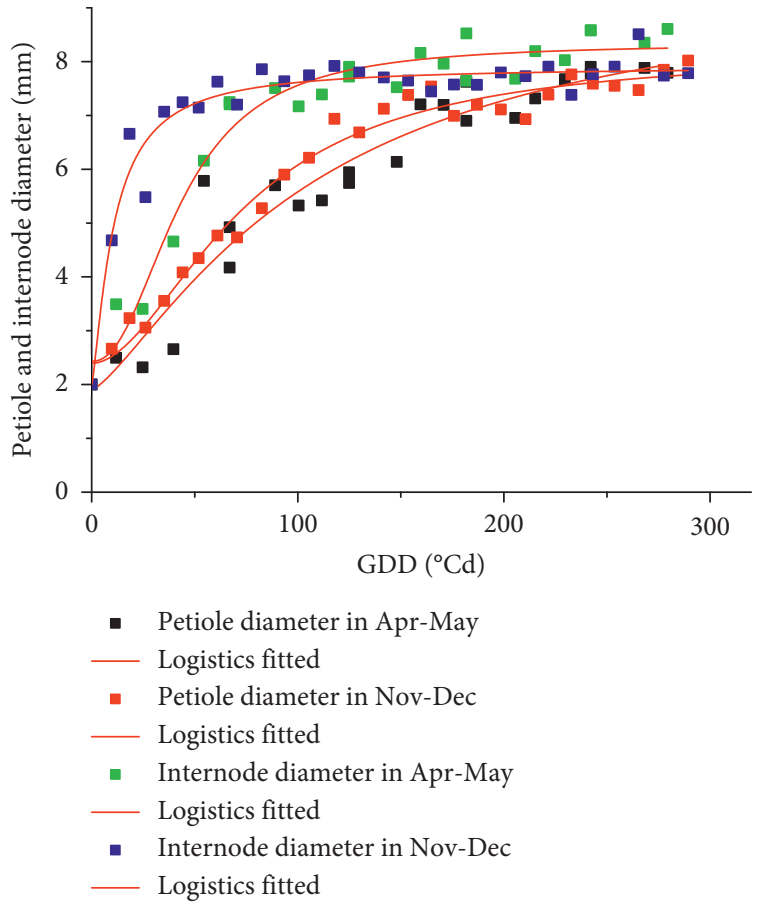

(d)

Figure 4: Leaf area expansion (a) and dry matter accumulation (b), petiole and internode length (c) and diameter increasing (d) following thermal time accumulation in Apr-May 2015 and Nov-Dec 2015. Measured data of leaf expansion and petiole and internode diameter increasing were fitted by logistic curves, while measured data of leaf dry matter accumulation and petiole and internode length increasing were fitted by Boltzmann curves.

factor that determines the reliability of the simulation results. At the field level, many research studies were conducted on 3D point cloud acquisition of field crop canopy based on UAV (unmanned aerial vehicle) and LiDAR $[22,23]$. Based on these 3D point clouds, plant height, ground cover, and above-ground biomass were obtained $[24,25]$. But these methodologies presented an underestimation of biomass and leaf area index and cannot extract the architecture parameters of individual plants from the canopy. In order to obtain more detailed $3 \mathrm{D}$ point clouds at the individual plant level, 3D laser scanner, 3D digitizing, and multiview imaging were used in plant and organ 3D point cloud acquisition [26, 27]. Using these methods, many specific morphological parameters of various crops have been achieved, such as leaf azimuthal angle, leaf length, and leaf area of maize [28]. Since the last few years, many 3D point cloud acquisition methods were used in plant $3 \mathrm{D}$ structural model construction at different scales, such as LIDAR, 3D laser scanner, 3D digitizing, and multiview imaging [29]. However, there are still many challenges in 


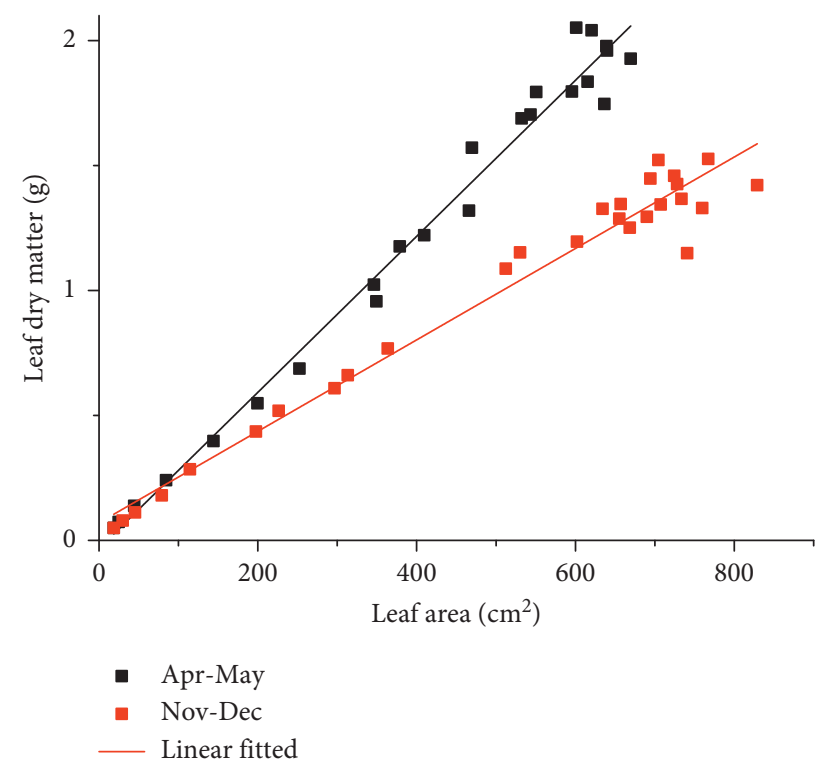

FIGURE 5: Correlation between leaf dry matter accumulation and leaf area expansion in different scenarios.

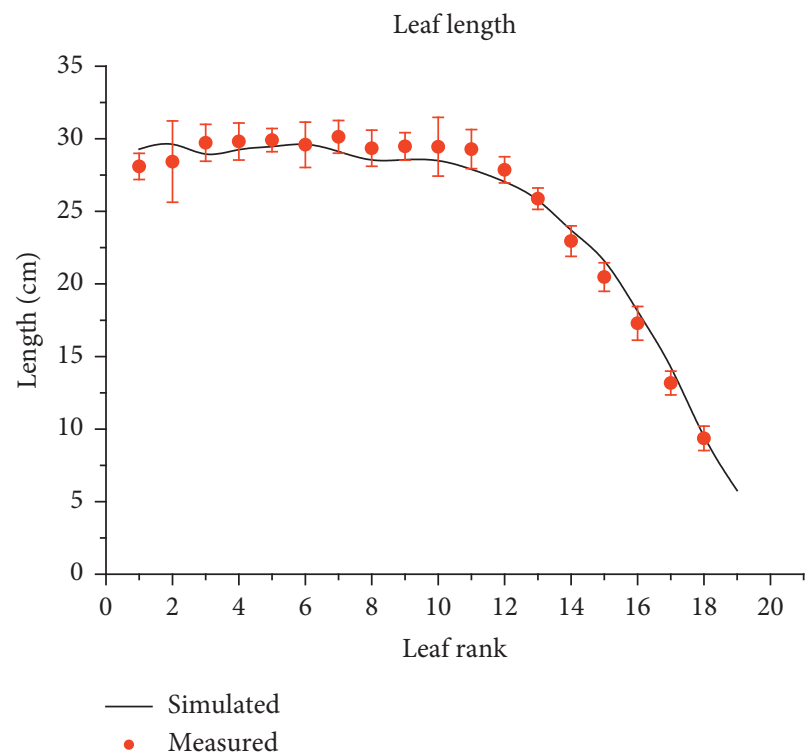

(a)

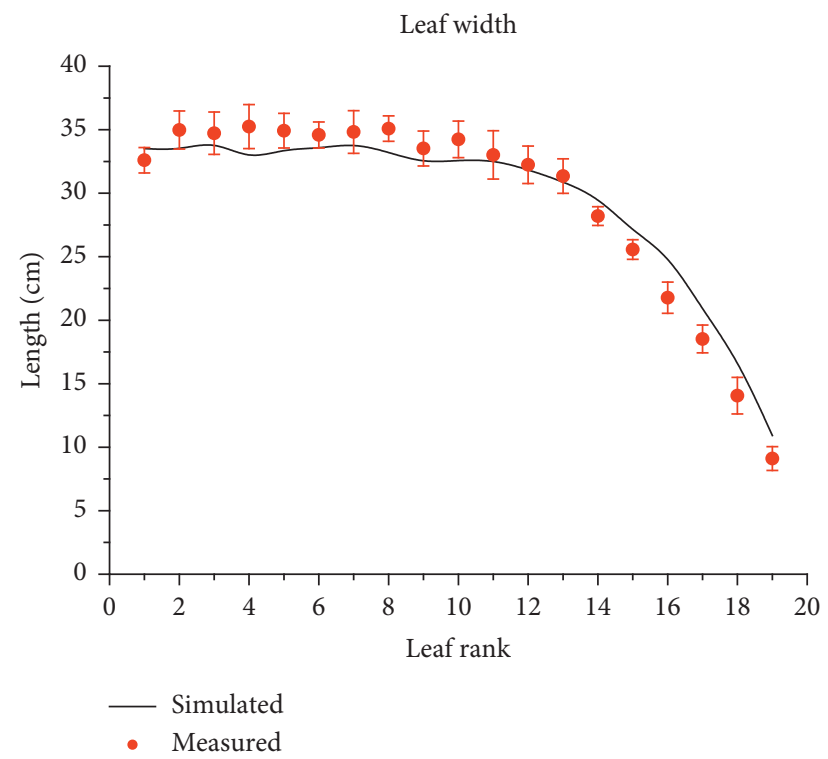

(b)

Figure 6: Continued. 


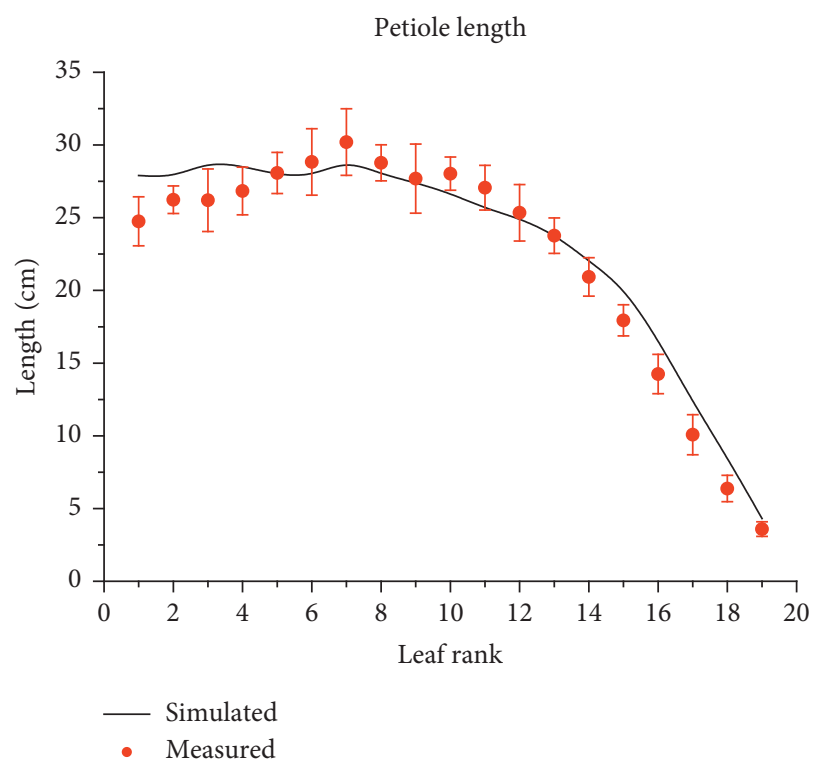

(c)

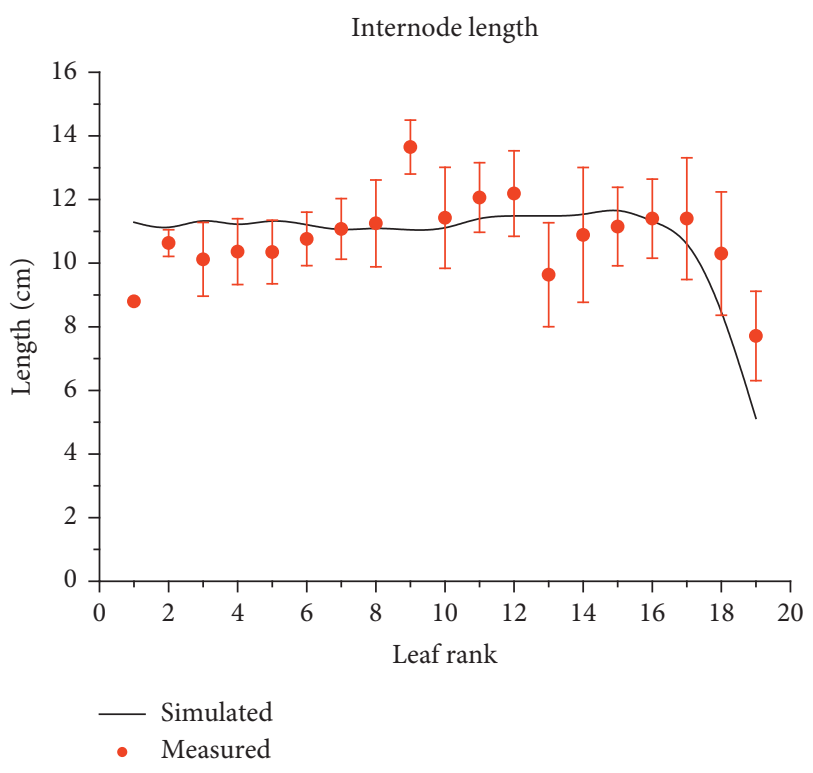

(d)

FIGURE 6: Comparison between the simulated and the measured value of leaf length, leaf width, petiole length, and internode length. Error bars indicate the SD.

TABLE 4: The bias, RMSD, and accuracy of the model simplifications for leaf length, leaf width, petiole length, and internode length.

\begin{tabular}{lccc}
\hline Structural parameters & \multicolumn{3}{c}{ Simulated } \\
& Bias $\left(\mathrm{cm}^{2}\right)$ & RMSD $(\mathrm{cm})$ & Accuracy \\
\hline Leaf length & -7.14 & 0.28 & 0.99 \\
Leaf width & -19.26 & 0.21 & 0.99 \\
Petiole length & 23.59 & 0.72 & 0.99 \\
Internode length & 0.97 & 0.57 & 0.99 \\
\hline
\end{tabular}

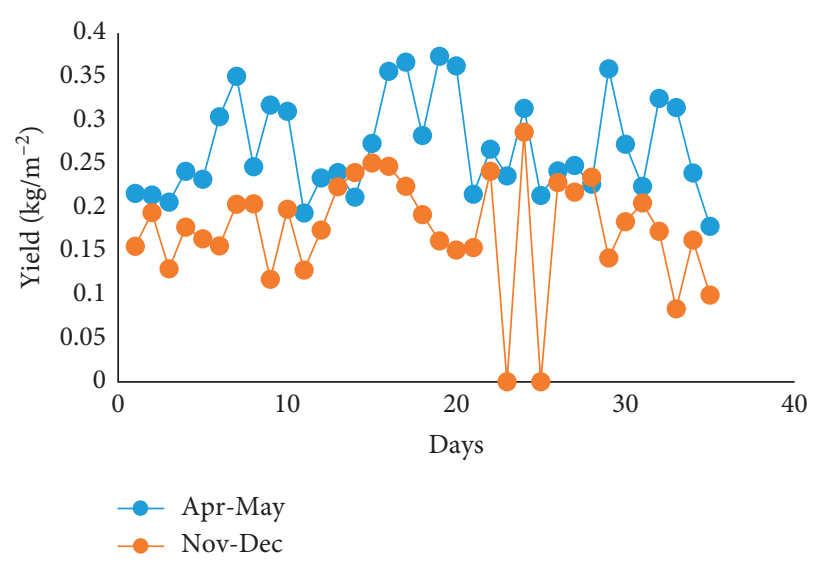

Figure 7: Measured cucumber yield per day in Nov-Dec and AprMay.

building a sufficiently accurate 3D model because plant morphologies are diverse for different species, and there is none uniform solution for all kinds of plants [28]. The

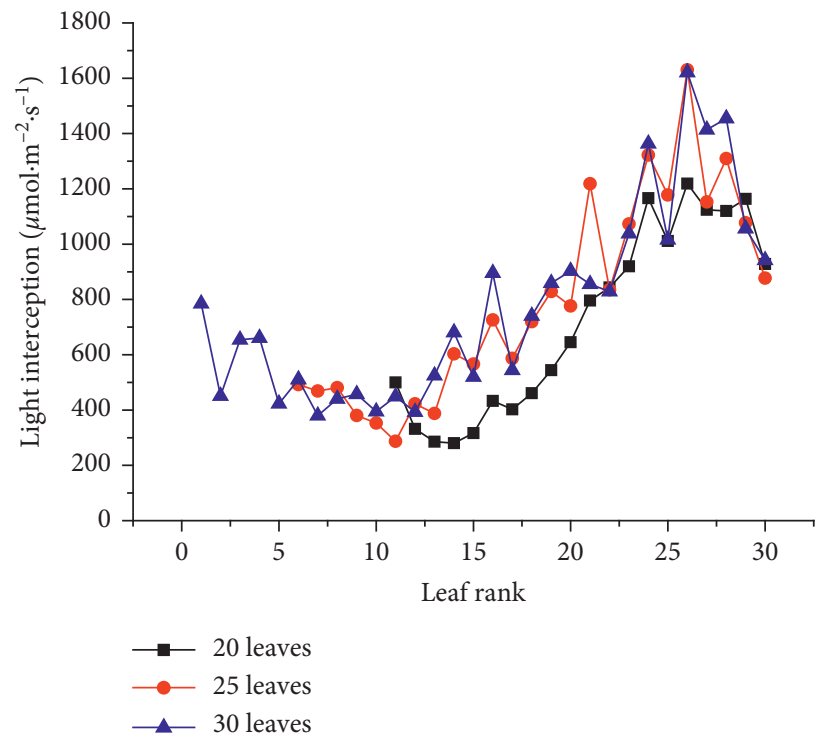

FIGURE 8: Light interception per leaf in the three canopies.

parametric modeling method applied in this study is also one of the alternative methods for constructing three-dimensional plants. Based on the descriptive model of organ expansion, a plant population with any number stands can be constructed. However, since the organ expansion model is a regression model, its adaptability is limited, and the simulation of the three-dimensional structure model is also constrained by the model. Therefore, we separately constructed the organ expansion curve equations in different scenarios (Apr-May and Nov-Dec) to construct the canopy growth accordingly. 


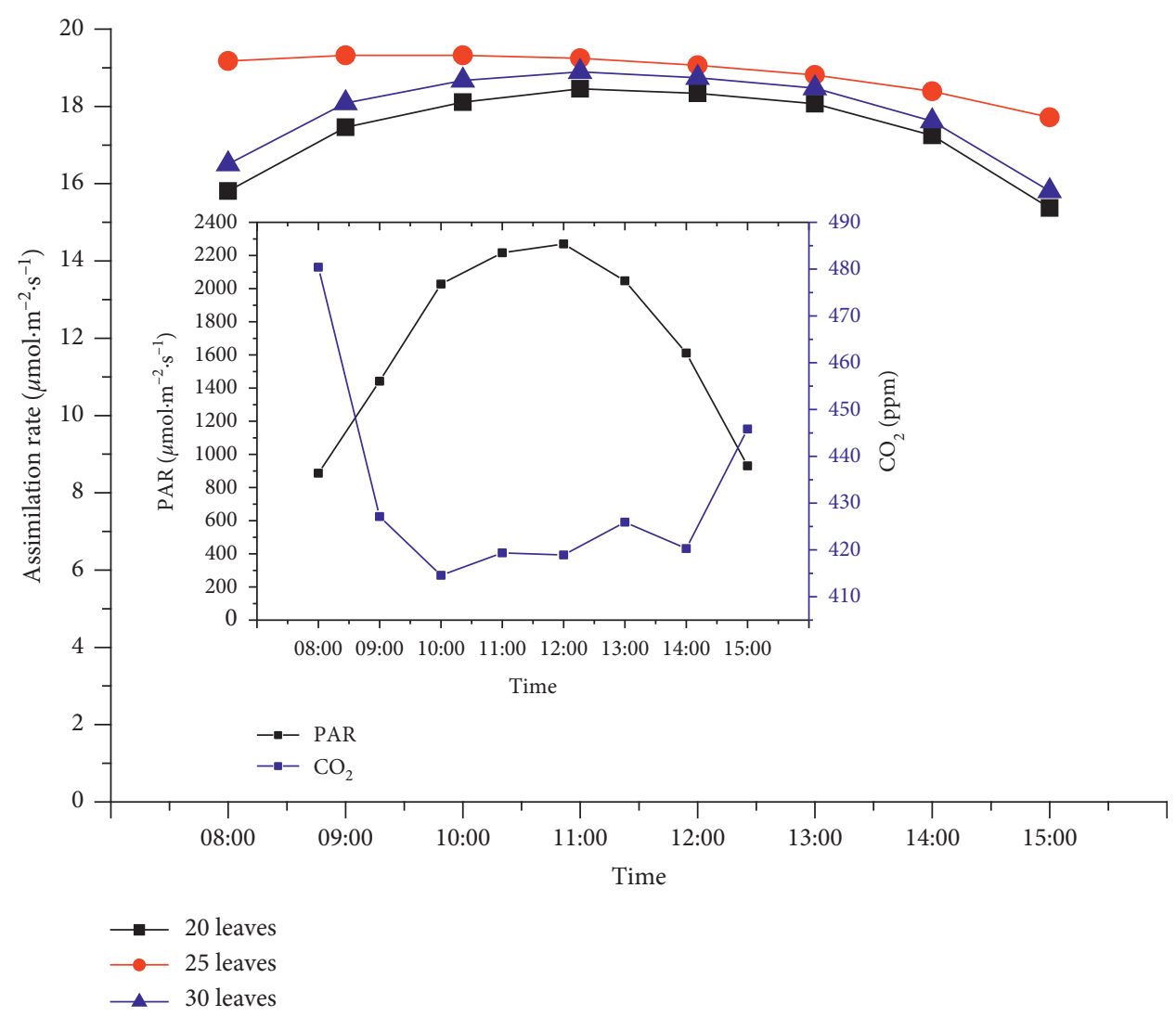

FIGURE 9: Diurnal variation of carbon dioxide assimilation rate per plant.

4.2. Light Energy on Cucumber Development. The effect of light on plant growth and development not only directly affects the photosynthetic reaction of leaves, but also affects plant morphogenesis. In most of the plant growth models, leaf area is an important parameter directly related to biomass accumulation and structural development [30]. However, the results of this study showed that leaf area is not completely positively related to dry matter. Cucumber grown in winter has larger leaf area but less dry matter, resulting in a smaller specific leaf area (SLA). Therefore, growth is more directly related to specific leaf area than to leaf area [31].

4.3. Photosynthesis Modeling. The photosynthetic capacity of leaves is affected not only by the amount of light intercepted, but also by the age of the leaves and the ambient temperature. In particular, cucumbers belong to C3 type plants, which have stronger photorespiration and growth respiration. They consume more assimilates than C4 plants to maintain growth and protect photosynthetic organs. In many research studies, various forms of equations were used to describe the response of FvCB model parameters to temperature, such as temperature sensitivity (Q10), polynomials, exponential functions, and normal distribution functions [32]. The change in temperature dependence of photosynthesis is caused by several factors such as $C_{i}, J_{\max }$, and $J_{\max }$ to $V_{c \max }$ ratio, which were also reported to change with growth temperature. The response of each factor to temperature seems to differ among species, and there is no report yet in cucumber. In the research of Zhou et al. [33], it is found that leaf aging significantly affected $A_{n}, A_{g}, R_{\text {dark, }}$, $V_{c \max }, J_{\max }, R_{\text {dark }} / A_{n}$, and $g_{s}$, but leaf aging had little effect on the $J_{\max } / V_{c \max }$ ratio, suggesting coordination between $V_{c \max }$ and $J_{\max }$ processes regardless of leaf age. Further studies are needed to reconfirm the leaf aging effect on the temperature sensitivity of $R_{\text {dark }}$ and to elucidate the mechanisms involved.

4.4. Optimal Utilization of Light Energy. In a semiclosed greenhouse, the $\mathrm{CO}_{2}$ concentration in the morning is significantly higher than at noon and afternoon (Figure 9). The main reason is that the respiration of plants at night accumulates a lot of $\mathrm{CO}_{2}$. From the photosynthesis simulation results, the high concentration of $\mathrm{CO}_{2}$ in the morning can obviously promote the leaf photosynthesis rate (Figure 9). At this stage, light intensity is the main factor limiting the assimilation rate. By noon, the light intensity increased, but the $\mathrm{CO}_{2}$ concentration decreased significantly and became the main factor limiting the rate of assimilation. Therefore, increasing light intensity in the morning or supplementing $\mathrm{CO}_{2}$ at noon can increase photosynthetic output. In the results of leaf light interception and photosynthesis rate analysis (Figures 8 and 10), the light interception and photosynthetic rate of the lower leaves in the 20-leaf canopy were significantly lower than those in the other two canopies. The main reason is that, in the parametric modeling process, 


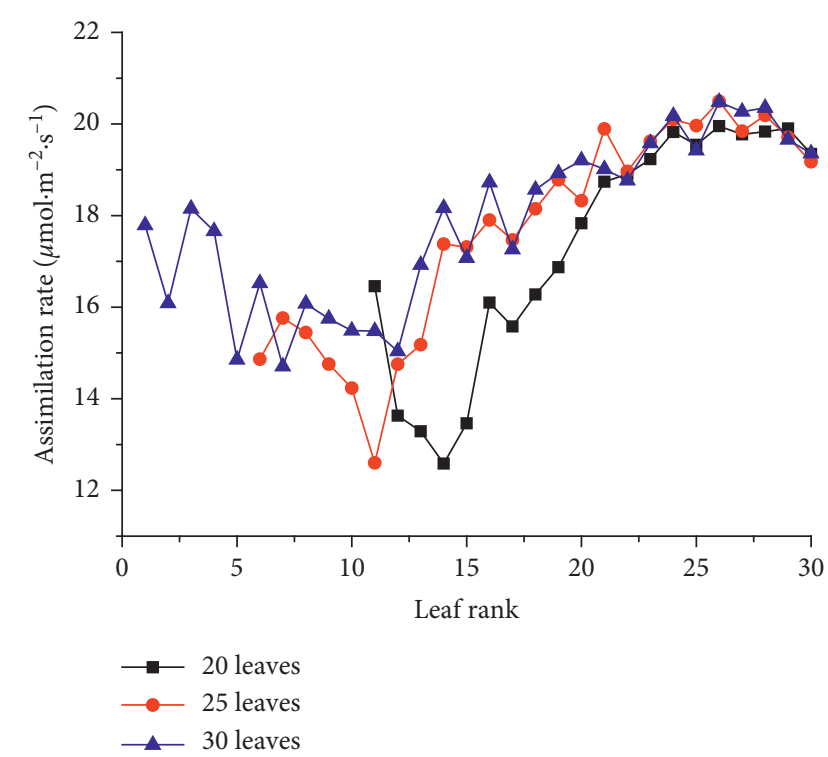

FIGURE 10: Net assimilation per day of leaves in the three canopies.

the blade azimuth model $\left(\varphi_{L}\right)$ we choose will make the blade distribution ratio in each azimuth range change with the LAI. As the LAI increases, more leaves will turn orientation towards rows with better lighting conditions to intercept more light. It can be seen that when the light conditions in winter are weak, maintaining a reasonable LAI is more conducive to canopy photosynthesis. From the results of this study, the 25-leaf canopy is the best canopy structure for light interception and photosynthesis. However, considering that the light interception of leaves under 20 leaves is weak and the leaf function is weak due to the effects of leaf senescence, the number of leaves in the canopy during winter should be controlled within 25 leaves.

\section{Conclusions}

Low temperature and low light energy in the winter of east China are important reasons for the decline in cucumber yield, especially in greenhouses without supplementary light. This study provides an important management basis for the optimal use of light in the greenhouse in winter. Using $3 \mathrm{D}$ modeling technology, the virtual structure model of $\mathrm{cu}-$ cumber canopy was established, and combined light interception modeling and photosynthesis modeling, the light environment in the canopy and the photosynthetic performance of leaves were quantitatively studied to obtain $\mathrm{cu}-$ cumber management strategies in winter. By using the $\mathrm{FvCB}$ model, Rubisco-limited $\left(A_{c}\right)$ and RuBP regeneration-limited $\left(A_{j}\right)$ assimilation rate of each leaf in three canopies with different leaves per plant were simulated, respectively. Based on the simulated result, we analyzed the effects of light and $\mathrm{CO}_{2}$ changes on the photosynthesis at different time periods and different leaf positions. Through a comparative analysis of photosynthetic characteristics in the virtual canopy, we have come up with strategies to improve the canopy photosynthetic capacity, and a suitable canopy structure that is conducive to winter canopy photosynthetic yields.

\section{Data Availability}

All data used during the study are available from the corresponding author by request (e-mail: qiantingting@saas.sh.cn).

\section{Conflicts of Interest}

The authors declare that there are no conflicts of interest regarding the publication of this paper.

\section{Authors' Contributions}

Tingting Qian and Xiuguo Zheng contributed equally to this work.

\section{Acknowledgments}

The authors would like to thank Dr. Feng Lu for her support during the preparation of this manuscript. This work was supported by Shanghai Agriculture Applied Technology Development Program of China (no. G2015060402), National Natural Science Foundation of China (no. 61762013), and Shanghai Science and Technology Commission Project of China (no. 19DZ2281300).

\section{References}

[1] T. Boulard, J.-C. Roy, J.-B. Pouillard, H. Fatnassi, and A. Grisey, "Modelling of micrometeorology, canopy transpiration and photosynthesis in a closed greenhouse using computational fluid dynamics," Biosystems Engineering, vol. 158, pp. 110-133, 2017.

[2] X. Ding, Y. Jiang, D. Hui et al., "Model simulation of cucumber yield and microclimate analysis in a semi-closed greenhouse in China," HortScience, vol. 54, no. 3, pp. 547-554, 2019.

[3] L. Marcelis, A. Broekhuijsen, E. Meinen, E. Nijs, and M. Raaphorst, "Quantification of the growth response to light quantity of greenhouse grown crops," in Proceedings of the International Symposium on Artificial Lighting in Horticulture, pp. 97-104, Lillehammer, Norway, June 2005.

[4] L. Marcelis, F. Maas, and E. Heuvelink, "The latest developments in the lighting technologies in Dutch horticulture," in Proceedings of the International ISHS Symposium on Artificial Lighting, pp. 35-42, Québec City, Canada, November 2000.

[5] T. Hovi, J. Näkkilä, and R. Tahvonen, "Interlighting improves production of year-round cucumber," Scientia Horticulturae, vol. 102, no. 3, pp. 283-294, 2004.

[6] X. Hao, X. Guo, X. Chen, and S. Khosla, "Inter-lighting in mini-cucumbers: interactions with overhead lighting and plant density," Acta Horticulturae, vol. 1107, no. 1107, pp. 291-296, 2015.

[7] X. Hao, X. Guo, J. Lanoue et al., "A review on smart application of supplemental lighting in greenhouse fruiting vegetable production," Acta Horticulturae, no. 1227, pp. 499-506, 2017.

[8] J. H. Kim, J. W. Lee, T. I. Ahn, J. H. Shin, K. S. Park, and J. E. Son, "Sweet pepper (Capsicum annuum 1.) canopy photosynthesis modeling using 3D plant architecture and light ray-tracing," Frontiers in Plant Science, vol. 7, p. 1321, 2016. 
[9] T.-T. Qian, S.-L. Lu, C.-J. Zhao, X.-Y. Guo, W.-L. Wen, and J.-J. Du, "Heterogeneity analysis of cucumber canopy in the solar greenhouse," Journal of Integrative Agriculture, vol. 13, no. 12, pp. 2645-2655, 2014.

[10] W. Wen, X. Guo, B. Li et al., "Estimating canopy gap fraction and diffuse light interception in 3D maize canopy using hierarchical hemispheres," Agricultural and Forest Meteorology, vol. 276-277, Article ID 107594, 2019.

[11] A. J. Burgess, R. Retkute, T. Herman, and E. H. Murchie, "Exploring relationships between canopy architecture, light distribution, and photosynthesis in contrasting rice genotypes using 3D canopy reconstruction," Frontiers in Plant Science, vol. 8, p. 734, 2017.

[12] R. P. A. Perez, C. Fournier, L. Cabrera-Bosquet et al., "Changes in the vertical distribution of leaf area enhanced light interception efficiency in maize over generations of selection," Plant, Cell \& Environment, vol. 42, no. 7, pp. 2105-2119, 2019.

[13] L. Tang, D. Yin, and C. Chen, "Optimal design of plant canopy based on light interception: a case study with loquat," Frontiers in Plant Science, vol. 10, p. 364, 2019.

[14] G. Buck-Sorlin, P. H. B. de Visser, M. Henke et al., “Towards a functional-structural plant model of cut-rose: simulation of light environment, light absorption, photosynthesis and interference with the plant structure," Annals of Botany, vol. 108, no. 6, pp. 1121-1134, 2011.

[15] T.-W. Chen, M. Henke, P. H. B. de Visser et al., "What is the most prominent factor limiting photosynthesis in different layers of a greenhouse cucumber canopy?" Annals of Botany, vol. 114, no. 4, pp. 677-688, 2014.

[16] R. P. A. Perez, J. Dauzat, B. Pallas et al., "Designing oil palm architectural ideotypes for optimal light interception and carbon assimilation through a sensitivity analysis of leaf traits," Annals of Botany, vol. 121, no. 5, pp. 909-926, 2017.

[17] Y. Y. Cho, S. Oh, M. M. Oh, and J. E. Son, "Estimation of individual leaf area, fresh weight, and dry weight of hydroponically grown cucumbers (Cucumis sativus 1.) using leaf length, width, and SPAD value," Scientia Horticulturae, vol. 111, no. 4, pp. 330-334, 2007.

[18] T. Qian, X. Zheng, X. Guo, W. Wen, J. Yang, and S. Lu, "Influence of temperature and light gradient on leaf arrangement and geometry in cucumber canopies: structural phenotyping analysis and modelling," Information Processing in Agriculture, vol. 6, no. 2, pp. 224-232, 2019.

[19] S. Lu, C. Zhao, X. Guo, W. Wen, and B. Xiao, "A new paradigm for fast interactive design of crops," Intelligent Automation and Soft Computing, vol. 16, pp. 1147-1155, 2010.

[20] G. D. Farquhar, S. von Caemmerer, and J. A. Berry, "A biochemical model of photosynthetic $\mathrm{CO}_{2}$ assimilation in leaves of C3 species," Planta, vol. 149, no. 1, pp. 78-90, 1980.

[21] K. Kahlen and H. Stützel, "Modelling photo-modulated internode elongation in growing glasshouse cucumber canopies," New Phytologist, vol. 190, no. 3, pp. 697-708, 2011.

[22] L. Lei, C. Qiu, Z. Li et al., "Effect of leaf occlusion on leaf area index inversion of maize using UAV-LiDAR data," Remote Sensing, vol. 11, no. 9, p. 1067, 2019.

[23] R. P. A. Perez, E. Costes, F. Théveny, S. Griffon, J.-P. Caliman, and J. Dauzat, "3D plant model assessed by terrestrial LiDAR and hemispherical photographs: a useful tool for comparing light interception among oil palm progenies," Agricultural and Forest Meteorology, vol. 249, pp. 250-263, 2018.

[24] J. A. Jimenez-Berni, D. M. Deery, P. Rozas-Larraondo et al., "High throughput determination of plant height, ground cover, and above-ground biomass in wheat with LiDAR," Frontiers in Plant Science, vol. 9, p. 237, 2018.

[25] S. Madec, F. Baret, B. de Solan et al., "High-throughput phenotyping of plant height: comparing unmanned aerial vehicles and ground LiDAR estimates," Frontiers in Plant Science, vol. 8, p. 2002, 2017.

[26] B. Elnashef, S. Filin, and R. N. Lati, "Tensor-based classification and segmentation of three-dimensional point clouds for organ-level plant phenotyping and growth analysis," Computers and Electronics in Agriculture, vol. 156, pp. 51-61, 2019.

[27] S. Wu, W. Wen, B. Xiao et al., "An accurate skeleton extraction approach from 3D point clouds of maize plants," Frontiers in Plant Science, vol. 10, p. 248, 2019.

[28] Y. Wang, W. Wen, S. Wu et al., "Maize plant phenotyping: comparing 3D laser scanning, multi-view stereo reconstruction, and 3D digitizing estimates," Remote Sensing, vol. 11, no. 1, p. 63, 2018.

[29] M. Vázquez-Arellano, H. Griepentrog, D. Reiser, and D. Paraforos, "3-D imaging systems for agricultural applications-a review," Sensors, vol. 16, no. 5, p. 618, 2016.

[30] L. F. M. Marcelis, E. Heuvelink, and J. Goudriaan, "Modelling biomass production and yield of horticultural crops: a review," Scientia Horticulturae, vol. 74, no. 1-2, pp. 83-111, 1998.

[31] S. M. Weraduwage, J. Chen, F. C. Anozie, A. Morales, S. E. Weise, and T. D. Sharkey, "The relationship between leaf area growth and biomass accumulation in Arabidopsis thaliana," Frontiers in Plant Science, vol. 6, 2015.

[32] K. Hikosaka, K. Ishikawa, A. Borjigidai, O. Muller, and Y. Onoda, "Temperature acclimation of photosynthesis: mechanisms involved in the changes in temperature dependence of photosynthetic rate," Journal of Experimental Botany, vol. 57, no. 2, pp. 291-302, 2005.

[33] H. Zhou, M. Xu, H. Pan, and X. Yu, "Leaf-age effects on temperature responses of photosynthesis and respiration of an alpine oak, Quercus aquifolioides, in southwestern China," Tree Physiology, vol. 35, no. 11, pp. 1236-1248, 2015. 